\title{
Father Prepared, Committed, and Involved in His Child's Birth: The Experience of Early Father-Child Skin to Skin Contact at Birth
}

\author{
Claudia Uribe-Torres ${ }^{1 *}$, Mónica Muñoz Serrano1, Luiza Hoga² \\ ${ }^{1}$ Nursing School, Faculty of Medicine, Pontificia Universidad Católica de Chile, Santiago, Chile \\ ${ }^{2}$ Nursing College, University of São Paulo, São Paulo, Brazil \\ Email: *curibet@uc.cl
}

How to cite this paper: Uribe-Torres, C., Serrano, M.M. and Hoga, L. (2021) Father Prepared, Committed, and Involved in His Child's Birth: The Experience of Early Father-Child Skin to Skin Contact at Birth. Open Journal of Obstetrics and Gynecology, 11, 853-867.

https://doi.org/10.4236/ojog.2021.117080

Received: May 31, 2021

Accepted: July 16, 2021

Published: July 19, 2021

Copyright $\odot 2021$ by author(s) and Scientific Research Publishing Inc. This work is licensed under the Creative Commons Attribution International License (CC BY 4.0).

http://creativecommons.org/licenses/by/4.0/

\begin{abstract}
Although the figure of the father has progressively gained a place in birth, it is still displaced and in the mere role of a companion. Objective: To understand the experience of fathers who have prepared to get actively involved in birth and to undergo the experience of early physical contact with their newborns. Method: A qualitative Action-Research (AR) design was carried out, which considered the antenatal educational intervention of 12 fathers together with their pregnant partners. After delivery, individual interviews were conducted in depth to collect the paternal experience at birth. Results: The central emerging theme developed during AR was "Paternal role and early bonding with the child", whereas the experience was comprehended in two central themes related to the meaning of the father-child encounter-contact: "The impact of the face-to-face encounter with the child"; "The first physical contact with the child, a key moment". Conclusion: The fathers who were prepared and involved from pregnancy and at birth attribute a special meaning to the father-child relationship which generated since the first encounter, allowing them to feel, enjoy and commit to care.
\end{abstract}

\section{Keywords}

Antenatal Preparation, Birth, Paternal Role, Father-Child Relationship

\section{Introduction}

The current efforts to recover the more human and understanding nature of the birth process have forced rethinking the place of the father in this process.

The social accompaniment of a significant other for the mother at birth has 
been one of the focuses of the global initiatives of comprehensive and humanized delivery, as promotion of a positive experience [1]. However, if referring to the father, the focus is on his role of companion and on the best interest of the woman's well-being [2], and very rarely does it refer to contributing the paternal benefit itself [3]. On the contrary, of the existing literature, some correspond to negative experiences in the father [4] [5], or aspects of the paternal role [6] in opposition to masculinity [4] [7]. Likewise, from the professionals' perspective, low or nonexistent recognition of the role that the father can play at birth has been reported [8] [9] [10]. He has even been considered as a depersonalized and marginalized actor of the pregnancy process, which is accentuated at birth [2]. In the same way, in situations where the father has been included in the birth process, the prevailing care model imposes paternal participation practices of a hegemonic and directive fashion, with scarce or nonexistent previous preparation, which can generate situations of stress and ambivalence in the fathers.

A number of theories regarding the development of fatherhood explain and value the father's involvement from pregnancy to child care in the postpartum period [11] [12]. Neuroscience indicates that an active social behavior by the father during pregnancy in close contact with the pregnant woman [13] would be related to hormone-associated changes, possibly causing a tender attitude, showing himself more sensitive and prone to affectionate contact and involvement with his newborn at birth [11], with a spontaneous tendency to caress and care for the child [13].

Recognizing the aforementioned benefits resulting from the behavior of an involved father committed to the pregnancy and delivery process, the proposal by some authors is to work on depersonalization and on the male roles at birth, in a different way than how the construction of motherhood is supported [4]. In this way, evidence has emerged with qualitative research studies that have raised personal phenomena of fathers who witness their children's birth, as well as actions to promote bonding with their newborn children [14] and that show the need for specific antenatal preparation for fathers [8] [15].

This article considers a proposal for the transformation of the fathers' experience during pregnancy and birth. The entire process of promotion of the antenatal paternal bonding and the father-child encounter at birth was set forth based on the Action-Research approach.

\section{Material and Method}

\subsection{Study Design and Methodologies}

A quali-quantitative study was conducted from 2016 to 2018. The qualitative stage corresponded, at first, to Action Research (AR) and in a second time to a closing process through an in-depth open interview. Both qualitative methodologies were conducted in the thesis of the Inter-unit PhD Program between two prestigious Latin American universities. The purpose of using AR, grounded on the critical paradigm [16], was to explore the needs for antenatal preparation to 
transform the reality of the male participants into a particular experience at birth. This investigative process, developed in three phases, allowed surveying the reality regarding the participation and involvement of the father in his child's birth and, later, developing educational actions together with the participants, according to their topics of interest.

The three phases of AR were directly linked to the three objectives of this methodology: 1) To learn the participants' reality and survey the generating themes, in its exploratory phase, 2) To jointly propose and implement the antenatal preparation educational sessions, in order to undergo a particular experience of the father-child encounter at birth, in its intervention phase, and 3) To jointly validate the intervention among researchers and participants, in the assessment phase.

The entire research process, during approximately one year, was conducted by means of focus groups of an exploratory nature and group work workshops, in a health network of the city of Santiago in the Chilean Metropolitan Region. The institution considers a mixed health system arranged in two geographical locations of the city to serve two segments of the population with different socio-economic levels. One of them corresponds, mainly, to the public system (institutionalized) and the other, to the private care system. The recruitment of the participants corresponded to the prenatal care in both outpatient centers of this care network.

After the prenatal preparation by AR and from the second week postpartum, the experience of the father-child encounter at birth was revealed through in-depth open interviews. This methodological process, framed in an interpretive paradigm, was designed and developed with the phenomenological approach.

\subsection{Participants}

A purposive sample of 12 male participants who accompanied their pregnant partners throughout pregnancy, were recruited: five from the private health system, and seven from the institutionalized public system, respectively. Participants were selected, depending on whether they were active companions of the pregnant women. Posters about the study were displayed in each prenatal control unit, so if they were interested in participating, they contacted the research team. Similarly, they could be motivated by their own pregnant partners. This means that the parents were admitted to the study according to their own interest and motivation to prepare for the birth.

Each participant was an adult and partner of the adult pregnant woman in her third trimester served in the health network, with a normal pregnancy when entering the study. Four subgroups were formed according to gestational age, with 2 to 3 men. From the first subgroup the need emerged to include the pregnant women as companions in the study, which forced, in consonance with the critical and participatory paradigm, to modify the study and optionally include the participation of the pregnant women. This option was replicated voluntarily in 
the other 3 subgroups. Finally, a total group was assembled for the preparation of 12 male participants and 11 pregnant women, who agreed to participate with prior process and signature of the Informed Consent form.

\subsection{Qualitative Information Analysis Process}

All the meetings of the AR process, from the exploratory phase to the assessment phase and closure, as well as the interviews conducted after birth, were recorded in an MP3 audio system and textually transcribed, safeguarding the participants' identities. Fantasy names were used to transcribe the reports: "soccer players" in the males from the private system and "colors" for the subgroup of the institutionalized public system. The field notes and the contents from the semi-structured questionnaires were considered as additional information.

Finally, thematic analysis was used for all qualitative information.

\subsection{Ethical Review}

The research procedures were developed according to Resolution No. 466/2012 of the Brazilian National Health Council and to Chilean Law No. 20,120, which regulates research in health. Favorable opinion of the Brazilian and Chilean University Scientific and Ethics Committees was also obtained, respectively.

\section{Results}

\subsection{Sociodemographic Background of the Participating Fathers}

The sociodemographic characteristics of the fathers who participated in the 2 stages of the study are detailed in Table 1 . When observing age by groups, the mean age in the private system was 32 years old, whereas in the group of the institutionalized system it was 36 years old, considering the extremes of 23 and 54 years old, respectively. Regarding the schooling level, a clear difference is observed in favor of the educational level of the participants from the private system of the health network.

Another aspect to highlight is the limited frequency of men with previous experience as fathers: only 3 participants of the total 12 were already fathers.

\subsection{Understanding the Reality of the Fathers (Exploratory Phase of AR)}

The information of this phase was obtained from different dynamics developed in the focus groups and from the participants' reflexive work. These results were mainly ordered around the paternal expectations regarding participation and involvement in their role as fathers. The desire to be part of their life "from the first moment" emerged strongly among the participants (Figure 1).

"It's a must-be-present moment for me, obviously unrepeatable, but it also means being part of it from day one, in my son's education, and that he can be sure that he'll have a present and active father in his education and growth throughout his life." (Medel, CSCA) 
Table 1. Participants by groups and sociodemographic characteristics.

\begin{tabular}{cccccccc}
\hline Participant & Age & $\begin{array}{c}\text { First time } \\
\text { father }\end{array}$ & Nationality & Schooling & Work activity & $\begin{array}{c}\text { Health } \\
\text { insurance }\end{array}$ Marital \\
status
\end{tabular}

Original Source: C Uribe-Torres PhD thesis entitled "Action-Research: An educational intervention for the promotion of early father-child contact in the context of birth” [thesis]. São Paulo: Nursing College, University of São Paulo, 2017.

"Starting as from the first moment is more ... like the affection and everything is enhanced a lot more when approaching for the first time, when seeing the child being born" (Calypso, HCUC).

\subsection{Generating Theme and Educational Requirements Associated with the Role of the Father and the Early Bonding with His Child}

In the explanatory phase, the generating theme was jointly determined, which would guide, as a central axis, the participants' antenatal preparation work to perform the paternal role and undergo the father-child bonding process, from pregnancy to birth (Figure 1).

The educational requirements included skills development in the scopes of knowing about the bonding process, how to feel the child since the antenatal stage, and practicing some techniques of physical contact with the child.

\subsection{Knowledge Educational Requirements}

Even if the fathers stated that they maintained good communication with their children through contact with the mother, they acknowledged their disadvantage in relation to their pregnant partners, who were in direct contact with their children 24 hours a day. The interest in knowing about several ways of being able to feel and interact with their children, through voice and touch, were educational needs that emerged in this stage (Figure 1). 
Results of both stages of qualitative methodology: AR process and Open in-depth interview
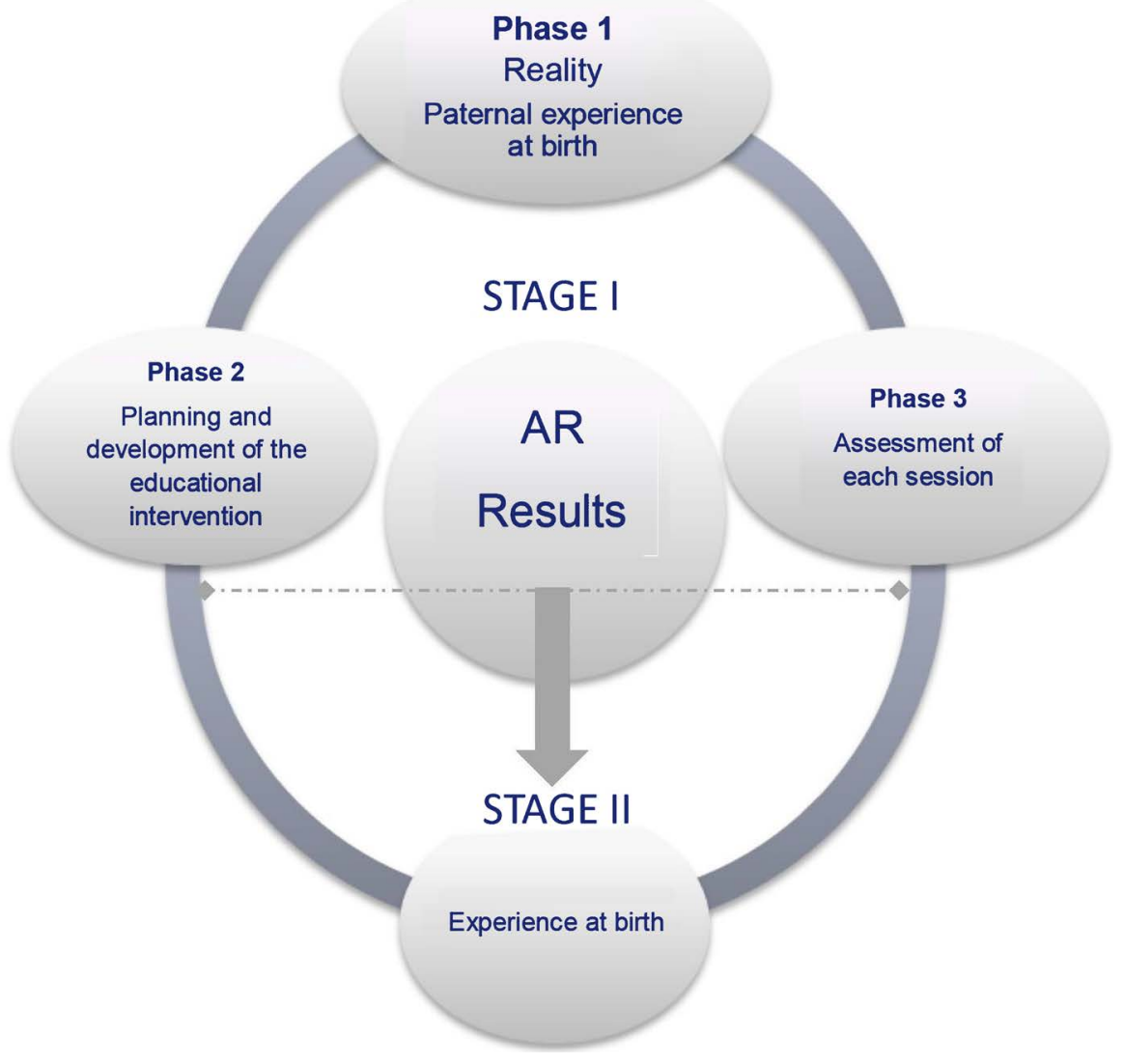

Figure 1. The entire research process is shown with its two stages, together with the different sources and data collection moments.

For the birth moment, the knowledge needs were targeted at the benefits of early mother-father-child contact, conferring absolute priority to the mother-child binomial and opening to the wish of having a moment that was exclusive to the father.

"I know that the mother is very much privileged and she's given the baby, immediately. Deep down, it is much more time with the mother, but I wish if it was possible, that there was some time for me ... that would be super positive." (Sánchez, CSCA)

\subsection{Educational Requirements in the Context of How to Establish a Bond}

These requirements focused on the need to develop skills and to acquire techniques for bonding and contact with the child, so so as to have the possibility of going through that experience (Figure 1).

"Learning how to have better contact, knowing how to better relate with the woman during delivery ... and how to better relate when the baby is born, how to get closer to it." (Red, HCUC) 


\subsection{Planning, Execution and Assessment of the Educational Workshops}

As in the exploratory phase, the intervention was planned and developed in a joint fashion between the participants and the researchers, based on the specific generating theme and on its requirements (Figure 1). With each public and private subgroup, it considered 2 full and exclusive sessions for the educational requirements around the father's role and early bonding with his child. Each educational session was developed in a flexible and dynamic manner, in order to modify or raise new educational requirements different from those originally established [17].

In the educational group workshops, the theoretical-practical dimensions were addressed including discussion contents, imagery dynamics for the antenatal father-child bonding, and the simulation methodology with newborn models, for skills development regarding father-child physical contact at the time of birth.

As a result of the first session, and in response to the antenatal bonding exercise, some fathers stated the sensations and emotions that had been generated during the imagery session: "I felt like her little head ... her little back like cuddled, in a crystalline water environment ... gray in color. I felt peace, and as if she felt safe in my hands." (Calypso, HCUC)

The assessment of this session showed the appreciation of the bond and interaction that can be established between the father and his child during pregnancy, with the purpose that, at the time of birth, the child can recognize his/her father. " $P m$ super aware of the bond. I find that it s super important and that the maternal and paternal affections must obviously be there from the first moment. I believe that touching, perceiving and feeling are super important. [...] That my baby realizes that the hands, are not the mother's hands, but the father's, which are a little stronger but soft. She must realize this bond from the very first moments, know when her mother is touching her and when it is the father's touch, and that she recognizes the voices before she's born." (Jade, HCUC)

The next educational session or workshop was related to the birth moment and to the mother-father-child encounter. The fathers and mothers participated in a reflection dynamics by means of the projection of images that showed different ways for the father to approach his newborn child. Subsequently, they watched a video on mother-child contact and discussed about the benefits, both for the woman and for the newborn. The analysis and reflection contents were around the benefits of this first encounter, the role of the father as a watchman and guardian of the mother-child contact and, similarly, of the importance of having an exclusive moment for the father to enter into physical contact with his child: "At delivery, I believe that the mother and child are the protagonists, at birth ... (he laughs) it's the three of us. mother, child and father." (Brown, HCUC)

The practical part of this workshop corresponded to the training that the fathers underwent holding the babies in their arms. Each of them interacted with 
the phantom in their arms, while they put into practice the different modalities of father-child skin-to-skin physical contact. Some of them even tried to practice how they would communicate with their child at that moment. Subsequently, they practiced giving and receiving the phantom among each other, each one suggesting the best way to hold the baby.

The assessment of this session focused on trust, on feeling capable, and with less fear of holding the children and entering into physical contact with them. Likewise, learning the skin-to-skin physical contact technique that the father could perform stood out, after such contact that the mother should previously perform with her newborn. It is to be noted that the concept of safety in this procedure (from the father's perspective) should take priority over emotionality, them being aware that they could enter into this physical contact, provided that the newborn's health status allowed so. "Today, I experienced it as going over a handbook. Having the concept of contact first and then understanding how it can be done, for how long, in which cases it is possible, and in which cases it is not." ( Gold, HCUC)

"Applying all that we've learned, from the real point of view, and in a safe manner." (Gray, HCUC)

\subsection{Understanding the Paternal Experience at Birth}

Fathers who participated in the first preparatory stage of the AR had the chance to enter into physical contact with their children at the time of birth, after the mother-child contact. In case the contact process had been postponed due to the newborn's health status, it took place in the same fashion before 6 hours postpartum (Figure 1).

Eight of twelve men participated in this post-birth stage of the study. The stories referring to their experiences were collected by means of open and in-depth interviews, from the second week postpartum. The interviews were conducted at home at a time previously agreed by the participants.

A guiding question, like, Could you tell me: How did you experience the childbirth and how did you involve with your baby? opened each of the 8 interviews. Additionally, a guide for auxiliary questions was available.

The reports of the participating fathers clearly focused on two major moments in which they felt involved and with active participation. The first moment corresponded to the delivery procedure, where they revealed their experience as their partners' companions and support. The second, and which concentrated an important part of their reports, corresponded to the moment experienced in the face-to-face encounter with their child in its real dimension, and where father-child physical contact could be consolidated.

\section{Face-to-Face: The First Father-Child Encounter}

The fathers went through different first-encounter experiences at birth, according to the delivery method. In their reports, it is shown that, since they witnessed 
the births, some fathers were experiencing their first encounter, even if it was only as spectators; others mentioned their first encounters when they managed to have contact with their children (Figure 2).

1) Feeling unique and indescribable emotions

Many of the fathers found it difficult to assign a name to the emotions experienced in this encounter; they refer to them as something indescribable, unique, where tears cannot be avoided.

"The moment when he's born is an indescribable sensation... seeing his little head coming out is an emotion that can't be described, it makes you want to cry out of joy." (Pinilla, CSCA)

"It was inevitable, when I saw him ... I was containing my tears, a unique emotion, so far." (Gold, HCUC)

\section{2) Feeling vulnerable and anxious at the child not crying}

Although it is true that, for most of the fathers, the birth moment represented a significant moment filled with emotion, for some of them this emotion was preceded by anguish and anxiety for not having the certainty that their children would be born without any problems. For them, the fact of having listened to their children crying added up a sensation of tranquility and confidence that everything was going well to the emotion they felt.

"Until the baby cried. It must have been at around two or three minutes, like he cried, made a moan, and we looked at each other, we were moved and cried at that moment. Deep down, it was but a relief to say: finally it's happening, it's true, he breathes, and he moves" (Sepia, HCUC)

Meanings attributed by parents to the experience of encountering and contact with their baby

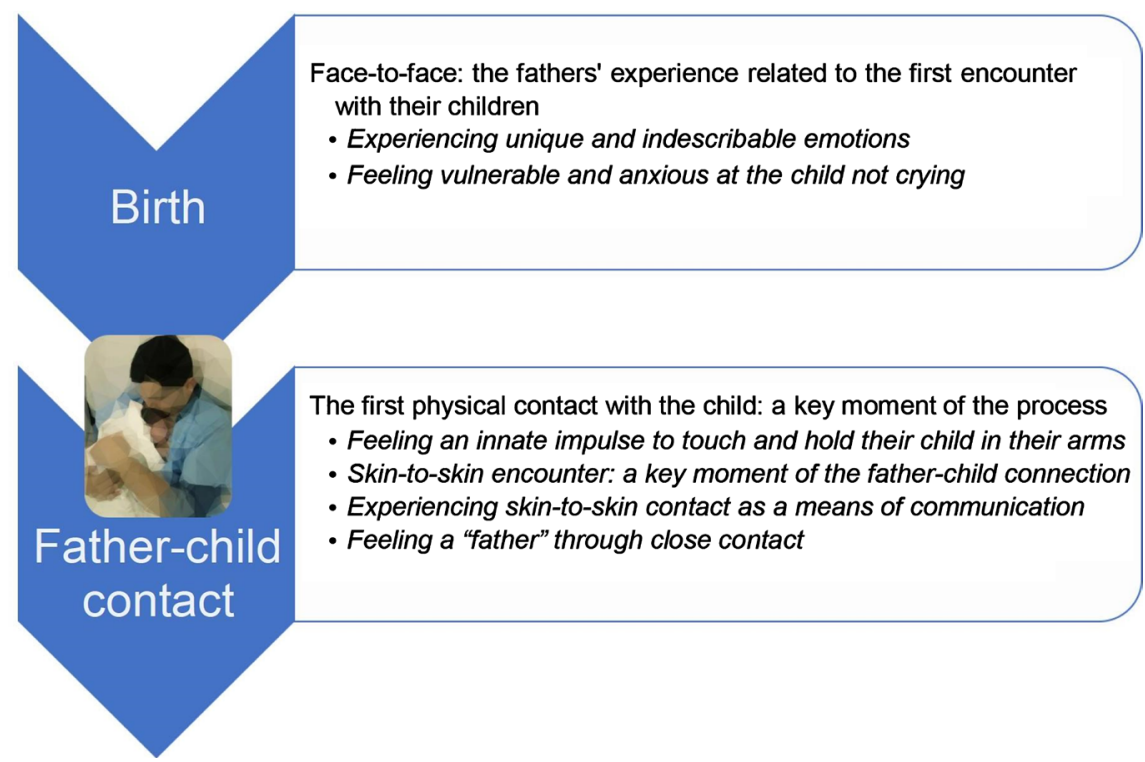

Figure 2. It corresponds to the organization of the results from the second stage, referring to the understanding of the experience lived. 


\subsection{First Physical Contact with the Child: A Key Moment of the Process}

The fathers reported in detail and with great emotionality the moment when the entered into physical contact with their children. They devoted most of the interview to report the experience, maintaining reflexive pauses and silences, showing the sensations and emotions they recalled from that moment. By means of their speeches, they tried to communicate the meaning that this close contact experience had for them.

\subsubsection{Feeling an Innate Impulse to Touch and Hold Their Child in Their Arms}

The fathers' instinct and desire to hold their children were one of the first manifestation of affection. In their reports it was shown that fears, reserve and insecurity (expressed in the exploratory phase) gradually dissipated as they entered into physical contact.

“That thing we talked about, fear of holding her, like I didn't feel it. What went through my head was like ... everything was instinctive in no time, that is, they passed her on to me, I grabbed her, I put her like this (taking his hands to his chest), I mean, it was incredible." (Messi, CSCA)

\subsubsection{Skin-to-Skin Contact: A Key Moment for the Father-Child Connection} The concept of father-child connection emerged spontaneously in almost all the reports. It was manifested as mutual union and devotion between both of them at the first encounter. When it occurred, when it was sealed and the meaning they attributed to the connection, are the details that filled the speeches with emotionality.

"I could touch it, feel it; it was there that I felt like a connection. I felt something inside of me, I felt that everything that I lived, that it was already real for me during pregnancy, was not even comparable to touching him. When you touch him you feel something in your soul, something that changed inside of me and there it was that tears fell from my eyes." (Gold, HCUC)

"I was more favored because I had more direct attachment really because I could put her here (he points to his chest). Feeling that warmth, I don't know if the word is 'baby smell', but her fingers so little, so fragile. Looking at her and saying 'we're finally here, it is you, I'm your father, you're my daughter', it was really too much emotion. In fact, I was crying at that moment because I found it too moving that I could hold her in my arms, something I was waiting for so long." (Jade, HCUC)

\subsubsection{Experiencing Skin-to-Skin Contact as a Means of Communication}

Some fathers wanted to report how they experienced their first communication moment with their children. Some did so in detail and in a very concrete manner, whereas others attributed the essential aspects of communication to silence 
and enjoyment of physical contact. Nevertheless, regardless of the way, all conveyed responsibility and commitment to protecting their child.

"I told the baby that, while I was there with her, she would lack nothing, nothing was going to happen to her, so that she felt protected with me. [...] you dream of being the ideal father, that she lacks nothing." (Brown, HCUC)

"This situation is like very rich, trying to connect to her in a silent language, but it does give a sense of responsibility towards what you have in your hands. It's like she gives you everything there and asks for everything at the same time." (Gray, HCUC)

"The sensation in indescribable, kind of emotion, responsibility, gratitude, everything. I felt like the responsibility, I felt that he needed me and that I needed him too [...] trying to express through the skin that he can count on me, that he's always going to have me." (Gold, HCUC)

\subsubsection{Feeling a "Father" through Close Contact}

Becoming a father and the extension of their self were two meanings attributed to the key and emotional moment of the first contact. Staying close to the child through the skin generated a sensation of the extension of existence. Likewise, the fact of having contemplated and sheltered that being, so waited for and who was "blood of his blood", made him aware that he had become a father.

"That moment was so marvelous because having your daughter close and in skin-to-skin contact was very strong ... wonderful. I felt that she was ... that she was the extension of my existence, she was like my continuation. I was there and I felt her so inside of me, that I felt that." (Brown, HCUC) "Crying ... because finally you know that you will be a father at last. The fact that she's blood of your blood, that she looks like the mother, that she's something completely yours. So waited for, a being that you're finally watching, feeling, you're sheltering her and having her at that moment, in attachment." (Jade, HCUC)

\section{Discussion}

The bonding process experienced by the fathers from pregnancy to the birth of their children represents a major marking experience [8] [18] [19]. Undoubtedly, experiencing it with professional monitoring during the antenatal stage is beneficial, especially when this is based on particular needs of the fathers and not only on the maternal preparation model [8] [9] [12] [14].

In this study, the AR framework allowed developing a special and participatory preparation process for fathers [19] [20]. However, it is to be noted that, to meet the intervention objectives, it is necessary to ensure that the fathers are involved in the pregnancy and committed to the birth moment [21]. Worldwide, this situation is seldom frequent nowadays [22], as a result of stress, lack of support and non-compliance of the father's expectations [23]. The fathers included 
in this study were active participants of the educational interventions, showing the particular needs to undergo the experience in the different roles, mainly their role as fathers.

During pregnancy, unlike some studies indicating that the fathers do not manage to bond with their children in the antenatal stage [2] [9], the participants stated the need to prepare themselves to establish interaction with their children since pregnancy, despite all the barriers related to lack of time and the biological difficulties that they present for this interaction.

The moment to receive and shelter their child at birth was a need which was widely expressed both by the fathers and by the accompanying mothers, unlike other studies in which they did not feel prepared [2] [24], or have not even had any knowledge of the benefits of skin-to-skin contact [25] [26].

The role of the father felt and experienced at birth was another aspect which was revealed with high intensity in this study. It can be determined that it meant the most relevant result of the research for the researchers.

For almost all the participants and in accordance with other studies, the key moment of birth corresponded to the face-to-face encounter with their children experienced as a unique and indescribable moment in life, in which the father-child connection is really established and where the bonding initiated during pregnancy is sealed [27]. For other researchers, it is revealed as a unique moment in life, singular and unforgettable, and which leaves emotional scars in the fathers [28].

In a general way, the fathers who participated in the study experienced birth as a unique and indescribable moment; however, the exact instant in which they established skin-to-skin father-child contact was signified by the participants as the consummation of the connection and relationship between both of them [27], as well as a milestone in benefit of fatherhood [29].

The study participants experienced sensitive and emotional openness to the moment of surrendering to father-child skin-to-skin contact. Some of them even pointed out that this sensory memory had marked them forever in the father-child relationship. The results also show that, when experiencing the sensations and emotions during contact, the fathers went beyond the limit of sensations, attributing specific meaning to the moment. The most relevant meanings attributed to the first skin-to-skin contact moment corresponded to the feeling of being a father and to the commitment to care.

Despite some authors refer that to feel like a father it would be enough only to witness the birth of the child [9] [27] [30], for other researchers who have deepened on the contact and fatherhood topic, there is a special and unique moment at birth that generates the sensation and feeling of being a father. This corresponds to the moment of skin-to-skin contact or to other close father-child contact instance, in which it is experienced that the child is blood of his blood, and it is real [2] [28] [29].

On the other hand, the fact of perceiving that they conveyed safety, tranquility 
and warmth to their children in a situation of vulnerability and dependence during skin-to-skin contact generated commitment to care in the fathers participating in the study. This moment was undoubtedly experienced as the space where they seal the pacts and promises of love and care [30]. For other authors, any form of father-child physical contact at birth generates commitment to care in the father [28].

This study allowed surveying paternal participation at birth, empowering men in their role as fathers and companions. For this being a fundamental aspect to be considered to encourage the birth process as a family, implementing it at a national level would undoubtedly be a major contribution to the country's social dimension.

Many challenges arise, among which is considering the father as a relevant actor from the moment of gestation; to include him actively in the antenatal preparation, and of course, to open a space for men, both physical and relational at the time of birth. The father, from the beginning, should feel like a caregiver, not just a collaborator with the mother.

A different approach from the other studies that have collected the experience that parents had to live at birth [23] [24], this study collected from these men the experience they expected to live.

If birth is experienced as a family and with active participation of the father, it can exert a future impact on the mental health and healthy bonding processes, both at the family and social levels.

\section{Conflicts of Interest}

The authors declare no conflicts of interest regarding the publication of this paper.

\section{References}

[1] World Health Organization (2018) WHO Recommendations: Intrapartum Care for a Positive Childbirth Experience. Green Ink, UK, 212 p.

http://apps.who.int/iris/bitstream/10665/260178/1/9789241550215-eng.pdf?ua=1\%0 http://www.who.int/reproductivehealth/publications/intrapartum-care-guidelines/e n/

[2] Longworth, H. and Kingdon, C. (2011) Fathers in the Birthroom: What Are They Expecting and Experiencing? A Phenomenological Study. Midwifery, 27, 588-594. https://doi.org/10.1016/j.midw.2010.06.013

[3] Williamson, M., McVeigh, C. and Baafi, M. (2008) An Australian Perspective of Fatherhood and Sexuality. Midwifery, 24, 99-107. https://doi.org/10.1016/j.midw.2006.07.010 http://www.ncbi.nlm.nih.gov/pubmed/17197059

[4] Dolan A. and Coe, C. (2011) Men, Masculine Identities and Childbirth. Sociology of Health \& Illness, 33, 1019-1034. https://doi.org/10.1111/j.1467-9566.2011.01349.x

[5] Hanson, S., Hunter, L.P., Bormann, J.R. and Sobo, E.J. (2009) Paternal Fears of Childbirth: A Literature Review. The Journal of Perinatal Education, 18, 12-20. https://doi.org/10.1624/105812409X474672 
[6] Barker, G., Greene, M., Siegel, E., Nascimento, M., Segundo, M., Ricardo, C., et al. (2010) What Men Have to Do with It. International Center for Research on Women (ICRW), Washington DC; Rio de Janeiro. https://www.icrw.org

[7] Adeniran, A.S., Aboyeji, A.P. and Fawole, A.A. (2015) Male Partner's Role during Pregnancy, Labour and Delivery: Expectations of Pregnant Women in Nigeria. International Journal of Health Sciences, 9, 301-309. https://doi.org/10.12816/0024697

[8] Nakano, A.M., Silva, L., Beleza, A.C., Stefanello, J. and Gomes, F. (2006) O suporte durante o processo de parturição: A visão do acompanhante. Acta Paulista de Enfermagem, 20, 131-137. https://doi.org/10.1590/S0103-21002007000200004

[9] Premberg, A. and Lundgren, I. (2006) Fathers' Experiences of Childbirth Education. The Journal of Perinatal Education, 15, 21-28. https://doi.org/10.1624/105812406X107780

[10] Singh, D. and Newburn, M. (2000) Becoming a Father: Men's Access to Information and Support about Pregnancy, Birth and Life with a New Baby. National Childbirth Trust in association with Fathers Direct, London.

[11] Maldonado-Durán, M. and Lecannelier, F. (2008) El padre en la etapa perinatal. Perinatología y Reproducción Humana, 22, 145-154.

[12] Premberg, A., Carlsson, G., Hellstr, A. and Berg, M. (2011) First-Time Fathers' Experiences of Childbirth. A Phenomenological Study. Midwifery, 27, 848-853. https://doi.org/10.1016/j.midw.2010.09.002

[13] Storey, A., Walsh, C., Quinton, R. and Wynne-Edwards, K.E. (2000) Hormonal Correlates of Paternal Responsiveness in New and Expectant Fathers. Evolution and Human Behavior, 21, 79-95. https://doi.org/10.1016/S1090-5138(99)00042-2

[14] Uribe, C., Contreras, A. and Hoga, L. (2018) Presencia activa del padre en el nacimiento integral: Significados atribuidos por padres y madres a los roles paternos. Revista chilena de obstetricia y ginecología, 83, 22-26. https://doi.org/10.4067/s0717-75262018000100022

[15] Hoga, L., Reberte, L., Higashi, A. and Zamo-Roth, F. (2013) The Experience and Role of a Companion during Normal Labor and Childbirth: A Systematic Review of Qualitative Evidence. Joanna Briggs Institute JBI Evidence Synthesis, 11, 121-156. https://doi.org/10.11124/jbisrir-2013-1178

[16] Melero-Aguilar, N. (2012) El paradigma crítico y los aportes de la investigación acción participativa en la transformación de la realidad social: Un análisis desde las ciencias sociales. Cuestiones pedagógicas, 21, 339-355.

[17] Thiollent, M. (2011) Metodologia da pesquisa ação. 18², Cortez, São Paulo, 69-70 p.

[18] Fenwick, J., Bayes, S. and Johansson, M. (2012) A Qualitative Investigation into the Pregnancy Experiences and Childbirth Expectations of Australian Fathers-to-Be. Sexual \& Reproductive Healthcare, 3, 3-9. https://doi.org/10.1016/j.srhc.2011.11.001

[19] Manganiello, A. and Hoga, L. (2012) Orgulho de pai: Cartilha educativa para promocão do envolvimento paterno na gravidez. University of São Paulo, São Paulo.

[20] Reberte, L. and Hoga, L. (2009) Celebrando a vida: Cartilha educativa. Nosso compromisso com a promoção da saúde da gestante, São Paulo.

[21] Yargawa, J. and Leonardi-Bee, J. (2015) Male Involvement and Maternal Health Outcomes: Systematic Review and Meta-Analysis. Journal of Epidemiology and Community Health, 69, 604-612.

http://jech.bmj.com/cgi/doi/10.1136/jech-2014-204784

https://doi.org/10.1136/jech-2014-204784 
[22] Guadagno, M., Mackert, M. and Rochlen, A. (2013) Improving Prenatal Health: Setting the Agenda for Increased Male Involvement. American Journal of Men's Health, 7, 523-526. https://doi.org/10.1177\%2F1557988313490785

[23] Saxbe, D., Horton, K.T. and Tsai, A.B. (2018) The Birth Experiences Questionnaire: A brief Measure Assessing Psychosocial Dimensions of childbirth. Journal of Family Psychology, 32, 262-268. https://doi.apa.org/doi/10.1037/fam0000365

[24] do Espirito-Santo, L.C. and Lourenzi, A.B. (2000) Expectativas, sentimentos e vivências do pai durante o parto e nascimento de seu filho. Revista Gaúcha de Enfermagem, 21, 87-109.

[25] Erlandsson, K. (2010) Prenatal Parental Education from the Perspective of Fathers with Experience as Primary Caregiver Immediately Following Birth: A Phenomenographic Study. The Journal of Perinatal Education, 19, 19-28. https://doi.org/10.1624/105812410X481537

[26] Erlandsson, K., Dsilna, A., Fagerberg, I. and Christensson, K. (2007) Skin-to-Skin Care with the Father after Cesarean Birth and Its Effect on Newborn Crying and Prefeeding Behavior. Birth, 34. 105-114.

http://www.ncbi.nlm.nih.gov/pubmed/17542814

https://doi.org/10.1111/j.1523-536X.2007.00162.x

[27] Sapién, J.S. and Isela, C.D. (2016) Significados que los padres atribuyen al feto durante el embarazo. Revista Electrónica de Psicología Iztacala, 19, 428-460.

[28] Jardim, D. and Penna, C. (2012) Pai-acompanhante e sua compreensão sobre o processo de nascimento do filho. Revista Mineira de Enfermagem, 16, 373-381.

[29] Freitas, W., Coelho, E. and Cavalcanti da Silva, A. (2007) Sentir-se pai: A vivência masculina sob o olhar de gênero. Cadernos de Saúde Pública, 23, 137-145. https://doi.org/10.1590/S0102-311X2007000100015

[30] Erlandsson, K., Christensson, K. and Fagerberg, I. (2008) Fathers' Lived Experiences of Getting to Know Their Baby While Acting as Primary Caregivers Immediately Following Birth. The Journal of Perinatal Education, 17, 28-36. https://doi.org/10.1624/105812408X298363 